\begin{tabular}{|c|c|}
\hline Citation & $\begin{array}{l}\text { W.A. Aregawi, T. Defraeye, P. Verboven, E. Herremans, G. De Roeck, B.M. } \\
\text { Nicolai, (2013), } \\
\text { Modelling of coupled water transport and large deformation during } \\
\text { dehydration of apple tissue, } \\
\text { Food and Bioprocess Technology, 6(8), 1963-1978. }\end{array}$ \\
\hline Archived version & $\begin{array}{l}\text { Author manuscript: the content is identical to the content of the published } \\
\text { paper, but without the final typesetting by the publisher }\end{array}$ \\
\hline Published version & http://dx.doi.org/10.1007/s11947-012-0862-1 \\
\hline Journal homepage & http://www.springer.com/food+science/journal/11947 \\
\hline Author contact & $\begin{array}{l}\text { bart.nicolai@biw.kuleuven.be } \\
+32(0) 16322375\end{array}$ \\
\hline IR & https://lirias.kuleuven.be/handle/123456789/345045 \\
\hline
\end{tabular}

(article begins on next page) 



\title{
Modelling of Coupled Water Transport and Large Deformation during Dehydration of Apple Tissue
}

\author{
Aregawi W.A. ${ }^{(1)}$, Defraeye $T^{(1)}$, Verboven $P^{(1)}$, Herremans $E .^{(1)}$, De Roeck ${ }^{(2)}{ }^{(2)}$ Nicolai B.M. ${ }^{(1)}$ \\ (1) BIOSYST-MeBioS, Katholieke Universiteit Leuven, W. de Croylaan 42, B-3001 Leuven, Belgium \\ (2) Division of Structural Mechanics, Department of Civil Engineering, Katholieke Universiteit Leuven, \\ Kasteelpark Arenberg 40, B-3001 Leuven, Belgium
}




\section{KULEUVEN}

\section{Abstract}

Water loss of fruit during storage has a large impact on fruit quality and shelf life, and is essential to fruit drying. Dehydration of fruit tissues is often accompanied by large deformations. One-dimensional water transport and large deformation of cylindrical samples of apple tissue during dehydration was modeled by coupled mass transfer and mechanics and was validated by calibrated X-ray CT measurements. Uni-axial compression-relaxation tests were carried out to determine the nonlinear viscoelastic properties of apple tissue. The Mooney-Rivlin and Yeoh hyperelastic potentials with three parameters were effective to reproduce the nonlinear behavior during the loading region. The Maxwell model was successful to quantify the viscoelastic behavior of the tissue during stress relaxation. The nonlinear models were superior to linear elastic and viscoelastic models to predict deformation and water loss. The sensitivity of different model parameters using the nonlinear viscoelastic model using Yeoh hyperelastic potentials was studied. The model predictions proved to be more sensitive to water transport parameters than to the mechanical parameters. The large effect of relative humidity and temperature on the deformation of apple tissue was confirmed by this study. The validated model can be employed to better understand postharvest storage and drying processes of apple fruit and thus improve product quality in the cold chain.

\section{Keywords}

apple, micro-CT, nonlinear viscoelastic models, water transport, cellular tissue, drying

\section{Nomenclature}

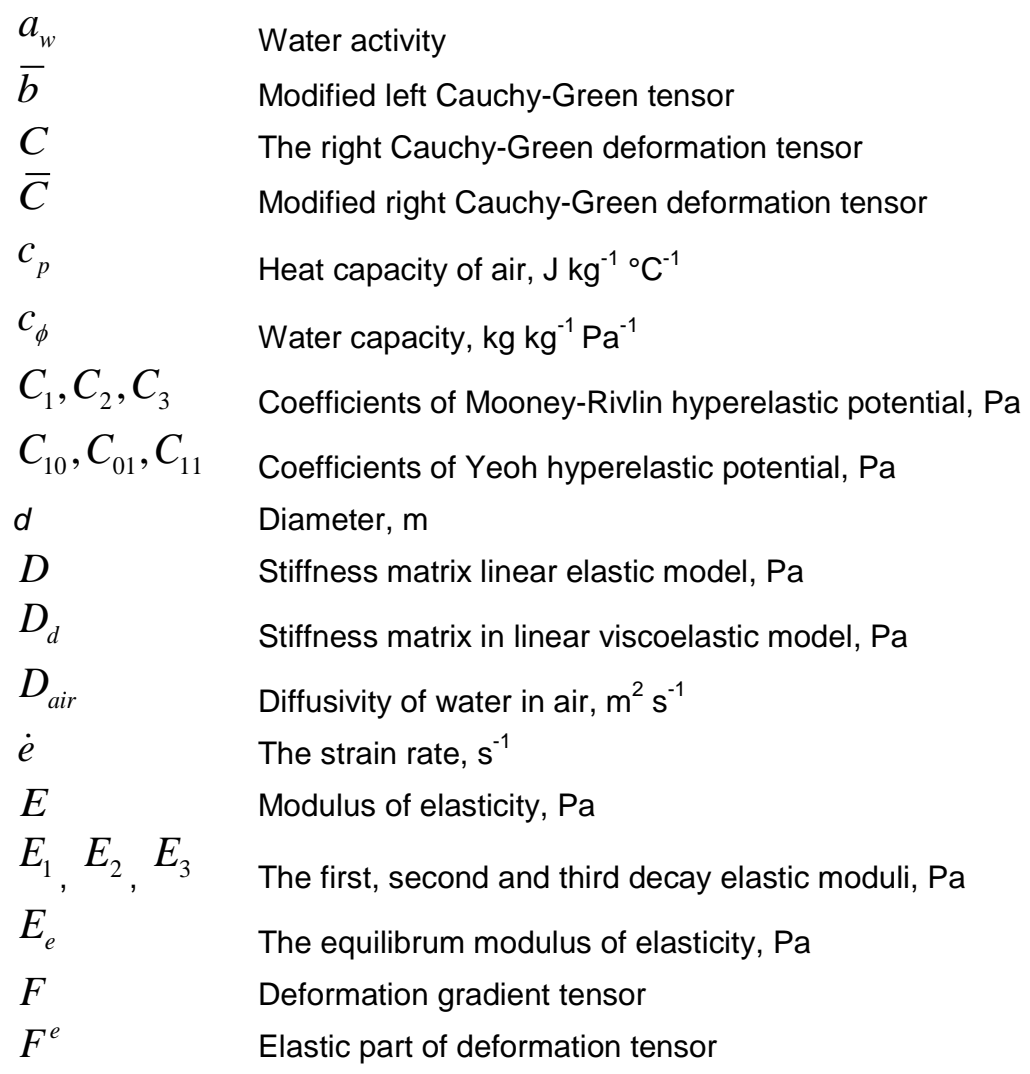




\begin{tabular}{|c|c|}
\hline$F^{s}$ & Swelling/shrinkage part of deformation tensor \\
\hline$F^{T}$ & Transpose of deformation gradient tensor \\
\hline$G$ & Shear modulus, $\mathrm{Pa}$ \\
\hline$h$ & Mass transfer coefficient, $\mathrm{m} \mathrm{s}^{-1}$ \\
\hline$h_{m}$ & Mass transfer coefficient, $\mathrm{kg}_{\mathrm{w}} \mathrm{m}^{-2} \mathrm{~Pa}^{-1} \mathrm{~s}^{-1}$ \\
\hline$h_{T}$ & Heat transfer coefficient, $\mathrm{Wm}^{-2 \circ} \mathrm{C}^{-1}$ \\
\hline$I$ & Second order identity tensor \\
\hline $\lg$ & Gray scale \\
\hline$\overline{I_{1}}$ & The first modified strain invariant \\
\hline $\bar{I}_{2}$ & The second modified strain invariant \\
\hline$J$ & Jacobian of the deformation \\
\hline$J^{e}$ & Jacobian of the elastic deformation \\
\hline$K$ & Hydraulic conductivity, $\mathrm{kg} \mathrm{s}^{-1} \mathrm{~m}^{-1} \mathrm{~Pa}^{-1}$ \\
\hline$K_{b}$ & Bulk modulus, $\mathrm{Pa}$ \\
\hline Le & Lewis number \\
\hline$n$ & Distance from surface, $\mathrm{m}$ \\
\hline $\mathrm{Nu}$ & Nusselt number \\
\hline$R$ & Universal gas constant, $8.314 \mathrm{~kJ} \mathrm{~mol}^{-1}$ \\
\hline $\operatorname{Re}$ & Reynolds number \\
\hline$R H_{\infty}$ & Relative humidity of the ambient air, $\%$ \\
\hline $\operatorname{Pr}$ & Prandtl number \\
\hline$q_{i}$ & The extension of the corresponding springs \\
\hline$Q_{\alpha}$ & Second Piola-Kirchhoff stress, $\mathrm{Pa}$ \\
\hline$S$ & Second Piola-Kirchhoff stress tensor, $\mathrm{Pa}$ \\
\hline$S_{q x}$ & Viscoelastic stress, $\mathrm{Pa}$ \\
\hline$S_{I S O}$ & Isochoric, $\mathrm{Pa}$ \\
\hline$S^{\infty}{ }_{I S O}$ & Equilibrium isochoric stress, $\mathrm{Pa}$ \\
\hline$S^{\infty}$ Vol & Equilibrium volumetric stress, $\mathrm{Pa}$ \\
\hline$t$ & Time, $\mathrm{s}$ \\
\hline$T$ & Temperature, $\mathrm{K}$ \\
\hline$U$ & Deformation, m \\
\hline V & Volume, $\mathrm{m}^{3}$ \\
\hline$V_{w}$ & Molar Volume of water, $18 \times 10^{-6} \mathrm{~m}^{3} \mathrm{~mol}^{-1}$ \\
\hline$x$ & Water content, $\mathrm{kg} \mathrm{kg}^{-1}$ \\
\hline$X_{\text {ref }}$ & Stress-free water content, $\mathrm{kg} \mathrm{kg}^{-1}$ \\
\hline
\end{tabular}

\section{Greek letters}
$\beta$
Volumetric shrinkage coefficient
$\beta_{\alpha}$
Nondimensional strain energy factor
$\Upsilon_{\alpha}$
Dissipative potential for the viscoelastic contribution 


\section{KULEUVEN}

$\Gamma_{\alpha} \quad$ Viscoelastic isochoric response, $\mathrm{Pa}$

$\varepsilon \quad$ Total strain

$\varepsilon^{d} \quad$ Shrinkage strain

$\varepsilon^{e} \quad$ Elastic strain

$\varepsilon_{x}, \varepsilon_{y}, \varepsilon_{z} \quad$ Elastic strain in the principal directions

$\varepsilon_{x y}, \varepsilon_{y z}, \varepsilon_{x z} \quad$ Shear strain

$\varepsilon_{0}$

Nominal initial strain

$\eta \quad$ Specific viscosity, Pa s

$k \quad$ Initial bulk modulus, $\mathrm{Pa}$

$\lambda_{1}, \lambda_{2}, \lambda_{3} \quad$ Stretch ratio in the three principal axes

$\lambda^{s} \quad$ Stretch ratio

$\lambda_{t} \quad$ Thermal conductivity, $\mathrm{W} \mathrm{m}^{-1}{ }^{\circ} \mathrm{C}^{-1}$

$\mu \quad$ Dynamic viscosity of air, $\mathrm{kg} \mathrm{m}^{-1} \mathrm{~s}^{-1}$

$\rho \quad$ Air density, $\mathrm{kg} \mathrm{m}^{-3}$

$\rho_{d m} \quad$ Dry mass density, $\mathrm{kg} \mathrm{m}^{-3}$

$\rho_{\text {sat }} \quad$ Saturated vapour density, $\mathrm{kg} \mathrm{m}^{-3}$

$\sum_{i=1}^{n} \Upsilon_{\alpha} \quad$ The dissipative potential

$\sigma \quad$ The Cauchy stress, $\mathrm{Pa}$

$\sigma(t) \quad$ The relaxaton stress, $\mathrm{Pa}$

$\tau_{\alpha} \quad$ Relaxation time, $\mathrm{s}$

$v \quad$ Poisson's ratio

$\phi \quad$ Water potential, $\mathrm{Pa}$

$\phi_{\infty} \quad$ Ambient water potential, $\mathrm{Pa}$

$\chi \quad$ Push-forward operation

$\psi_{\text {VOL }}^{\infty} \quad$ Volumetric elastic response

$\psi_{\text {ISO ISO }}^{\infty} \quad$ Isochoric elastic response 


\section{Introduction}

Fresh fruit such as apple is mainly composed out of water. During postharvest storage at low relative humidity, water from the fruit cells is lost, which is accompanied by hygrostresses. This leads to a decrease of the volume of the cells and thus of the total volume and mass of the fruit. This weight loss decreases the commercial value of the fruit. In addition, the shrinkage of the fruit tissue, as result of these hygrostresses, has a negative effect on the quality of the fresh product, due to changes in shape, shrivelling and loss of volume, which reduces the consumer acceptance. Apart from storage, dehydration of fruit tissue and the resulting hygrostresses are important for fruit drying processes, with respect to the quality of the dried fruits and the enhancement of drying process efficiency in terms of energy usage and production time. To study these dehydration processes, mechanical deformation of fruit tissue, as a result of hygrostresses, needs to be understood in addition to water transport. Apart from experiments, numerical models can be used to investigate dehydration processes in different fruit tissues, e.g. with respect to process parameters such as the relative humidity and temperature of the air. Such numerical models should include both water transport and (large) mechanical deformations, which are essentially coupled.

With respect to water transport modeling in cellular tissues, complex mechanisms have to be accounted for, where most of them are controlled by the plant cells (Taiz \& Zeiger, 2002). For practical purposes, water loss in fruit is often modelled as a lumped process, which assumes no internal water gradients in the tissue (e.g., Amarante et al., 2001; De Smedt et al., 2002). Such models offer no insight in the actual transport processes within the tissue. More advanced models do include the transport in the tissue, e.g. based on Fick's law or more elaborate equations for transport of mass. There are two basic approaches: the microscopic approach and the macroscopic approach. The microscopic approach recognizes the heterogeneous structure of the tissue, where the complex cellular structure is represented explicitly by a geometrical model (Marcotte et al., 1991; Toupin et al., 1989; Yao \& Le Maguer, 1996). On the other hand, the macroscopic approach considers the tissue as homogeneous, where lumped properties are used for modeling, which are representative for the ensemble of pores, cell walls, cell membranes and cell vacuoles. The macroscopic approach is most commonly used for transport modeling in fruit. Macroscopic water transport in fruit has been analyzed and modeled by, amongst others, Veraverbeke et al. (2003a; 2003b) for apple, and Nguyen et al. (2006a; 2006b; 2007) for pear, which all adopted a continuum approach based on Fick's second law of diffusion.

With respect to modeling mechanical deformation of fruit tissue, most models are based on continuum mechanics. It is often assumed that the biologic material behaves as a nonlinear viscoelastic continuum. In the simplest approach, the volume change due to the shrinkage of the tissue is assumed equal to the volume of water removed from the material (Gekas et al., 1995; Mayor \& Sereno, 2004; Piotr et al., 2004; Janjai et al., 2008a; 2008b). The principle of virtual work has been applied to hygrostress formation, where the deformation during heat and moisture transfer is based on linear elasticity theory (Irudayaraj \& Haghigh, 1992; Izum et al., 1995; Itaya et al., 1995; Akiyama et al., 2000; Yang et al., 2001; Inazu et al., 2005; Kowalski, 2005; Banaszak et al., 2002; Niamnuy et al., 2008). For water loss of fruit, the deformation of the tissue is often large.

The formulation of coupled mass transport and large deformations has already been applied in different research areas: thermal oxidation of silicon (Garikipati et al., 2001), the mechanics of solids with a growing mass (Lubarda et al., 2002), diffusion of a fluid through an elastic solid undergoing large deformations (Srinivasa et al., 2004), baking of bread (Zhang et al., 2005), species migration in finitely strained solids with application to polymer network swelling (Duda et al., 2010), microwave puffing (Rakesh \& Datta, 2011)

Published version: http://dx.doi.org/10.1007/s11947-012-0862-1 


\section{KU LEUVEN}

and fluid permeation in combination with large deformations for elastomeric materials (Anand et al., 2010). However, efforts devoted to modeling hygro-mechanical behavior of cellular foods, such as fruit, have so far been limited to small deformations.

The objective of this paper is to develop and validate a transient coupled water transport and mechanical deformation model for apple tissue of Malus domestica Borkh., cv. Jonagold and cv. Jonagored, which is able to cope with large deformations. A comparison is made between linear elastic, linear viscoelastic and nonlinear viscoelastic models. The models are calibrated using compression-relaxation tests and are validated using experimental data from X-ray CT measurements. First, the models for water transport and for mechanical deformation are presented. Afterwards, the model parameters are calibrated by means of experiments. Finally, the models are validated and the sensitivity to the model parameters is investigated.

\section{$2 \quad$ Materials and methods}

\section{$2.1 \quad$ Water transport model}

A macroscopic phenomenological approach is used, where water moves in the tissue as a consequence of a gradient in water potential (Nguyen et al., 2006a):

$\rho_{d m} c_{\phi} \frac{\partial \phi}{\partial t}=K \nabla^{2} \phi$

Reference is made to the nomenclature list for a detailed description of all model parameters. The water capacity $\left(c_{\phi}\right)$ can be derived from the sorption isotherm curve, which relates the water content $(X)$ to the water potential $(\phi)$, via the water activity $\left(a_{w}\right)$ (see section 3.1):

$c_{\phi}=\frac{\partial X}{\partial \phi}$

This moisture-isotherm relationship has been measured for Jonagold apple cortex tissue by (Veraverbeke et al., 2003a) at a temperature of $1^{\circ} \mathrm{C}$. Later, Nguyen et al. (2004; 2006a) showed that temperature only has a moderate effect on the isotherm for fruit cortex tissues. The hydraulic conductivity of apple tissues $(K)$ has been measured by (Veraverbeke et al., 2003a). In the present study, the hydraulic conductivity is assumed constant.

\subsection{Mechanical deformation models}

Linear elasticity theory can be used for small deformations (infinitesimal small strains). For a quasistatic case the mechanical equilibrium without body and external force is given by:

$\nabla \cdot \sigma=\nabla \cdot D\left(\varepsilon^{e}\right)=0$

The total strain $(\varepsilon)$ is the sum of the mechanical strain due to elasticity $\left(\varepsilon^{e}\right)$ and the shrinkage strain $\left(\varepsilon^{d}\right)$ :

$\varepsilon=\varepsilon^{e}+\varepsilon^{d}$ 


\section{KU LEUVEN}

The shrinkage strain results from water gradient, which can be determined as follows (Kowalski \& Rajewska, 2002; Lima et. al., 2002; Rambert et. al., 2006):

$\varepsilon^{d}=\beta\left(X-X_{r e f}\right)$

Where $\left(X-X_{\text {ref }}\right)$ denotes the water content difference with reference to the stress-free water content $\left(X_{\text {ref }}\right)$ at the start of dehydration, and $\beta$ is the volumetric shrinkage coefficient:

$\beta=\frac{1}{V} \frac{\partial V}{\partial X}$

Materials undergoing large deformations, e.g., during drying, should be described by nonlinear elasticity theory. The stresses in a material are calculated from the following mechanical equilibrium, assuming no body and surface forces (Bonet \& Wood, 1997):

$\nabla \cdot\left(S \cdot F^{T}\right)=0$

Where $\nabla \cdot(\bullet)$ is the divergence operator, $F^{T}$ is the transpose (i.e., superscript ${ }^{T}$ ) of the deformation gradient tensor and $S$ is the second Piola-Kirchhoff stress tensor. For nonlinear modelling, the relation between elastic strain and shrinkage strain, similar to Eq. (4), will be clarified in (section 2.2.3).

The aforementioned stress and strain relationships are required to solve the mechanical equilibrium balance equation for both small strain and large deformations. Three different models: a linear elastic, a linear viscoelastic and a nonlinear viscoelastic model are considered and discussed in the following sections (sections 2.2.1-2.2.3).

\subsubsection{Linear elastic model}

Materials exhibiting linear elasticity obey Hooke's law, which correlates the stress $\sigma$ with the infinitesimal strain $\varepsilon^{e}$ by the stiffness matrix $D$. The resulting stress-strain relationship for a linear elastic material is given by:

$$
\sigma=D \varepsilon^{e}=D\left(\varepsilon-\varepsilon^{d}\right)
$$

$$
D=\frac{E}{(1+v)(1-2 v)}\left[\begin{array}{cccccc}
1-v & v & v & 0 & 0 & 0 \\
v & 1-v & v & 0 & 0 & 0 \\
v & v & 1-v & 0 & 0 & 0 \\
0 & 0 & 0 & \frac{1-2 v}{2} & 0 & 0 \\
0 & 0 & 0 & 0 & \frac{1-2 v}{2} & 0 \\
0 & 0 & 0 & 0 & 0 & \frac{1-2 v}{2}
\end{array}\right]
$$

The total strain and shrinkage strain are given by:

$$
\begin{aligned}
& \varepsilon=\left[\begin{array}{llllll}
\varepsilon_{x} & \varepsilon_{y} & \varepsilon_{z} & \varepsilon_{x y} & \varepsilon_{y z} & \varepsilon_{x z}
\end{array}\right]^{T} \\
& \varepsilon^{d}=\left[\begin{array}{llllll}
\varepsilon^{d} & \varepsilon^{d} & \varepsilon^{d} & 0 & 0 & 0
\end{array}\right]^{T}
\end{aligned}
$$

The elastic strain $\left(\varepsilon^{e}\right)$ is thus represented as the difference between the total strain $(\varepsilon)$ and the shrinkage strain $\left(\varepsilon^{d}\right)$, where the latter is assumed isotropic (no shear components). 


\section{KU LeUVEN}

\subsubsection{Linear viscoelastic model}

Fruits exhibit viscoelastic behavior because of their solid and fluid components (Kim et al., 2008). The viscoelastic behavior of materials can be modeled by a system of connected springs and dashpots. The Maxwell model is considered in this study, which is the most common model to characterize the viscoelasticity of fruit tissue (Kim et al., 2008; Nicoleti et al., 2005; Wang, 2003). The springs in the Maxwell model represent the elastic component of the response that instantaneously deform upon the application of a load and immediately relax upon the release of the load. The dashpots represent the viscous components, where the displacement increases with time as long as a load is applied. The general Maxwell model is shown in Figure 1 with three Maxwell elements. Previous studies usually applied one or two Maxwell elements (Kim et al., 2008; Nicoleti et al., 2005; Wang, 2003). In this study, three Maxwell elements were applied for increased model accuracy.

Similar to elastic materials, the linear viscoelastic stress-strain relationship has the following expression (COMSOL, 2008):

$\sigma=D_{d}\left(\varepsilon-\varepsilon^{d}\right)+K_{b}\left(\varepsilon-\varepsilon^{d}\right)+S_{q x}$

$D_{d}=G\left[\begin{array}{cccccc}\frac{4}{3} & \frac{-2}{3} & \frac{-2}{3} & 0 & 0 & 0 \\ \frac{-2}{3} & \frac{4}{3} & \frac{-2}{3} & 0 & 0 & 0 \\ \frac{-2}{3} & \frac{-2}{3} & \frac{4}{3} & 0 & 0 & 0 \\ 0 & 0 & 0 & 2 & 0 & 0 \\ 0 & 0 & 0 & 0 & 2 & 0 \\ 0 & 0 & 0 & 0 & 0 & 2\end{array}\right]$

$G=\frac{E}{2(1+v)}$

$K_{b}=\frac{E}{3(1-2 v)}$

The viscoelastic stress is defined as:

$S_{q x}=G_{1} q_{1}+G_{2} q_{2}+G_{3} q_{3}$

$\mathrm{S}_{\mathrm{qx}}$ represents the viscoelastic stress of the three Maxwell elements (spring and dashpot in series, Figure 1) excluding the purely elastic effects, i.e. the free spring, which is connected in parallel with the Maxwell elements. In the model, the strain due to each spring $\left(q_{i}\right)$ is determined from the total strain rate $(\dot{e})$ in a single Maxwell element and the relaxation time $\left(T_{i}\right)$, according to following equation:

$\dot{q}_{i}+\frac{q_{i}}{\tau_{i}}=\dot{e}$

The first term in Eq. (17) represents the strain rate of the viscous part, due to the damper, and the second term represents the strain of the elastic part, due to the spring. The parameters $\left(G_{1}, G_{2}, G_{3}\right.$ from $E_{1}, E_{2}, E_{3}$ according to Eq.(14), and $\tau_{1}, T_{2}, T_{3}$ ) are to be determined from experiments (see section 3.2). 


\subsubsection{Nonlinear viscoelastic model}

Linear elastic models (linear stress-strain) do not accurately quantify the observed mechanical behavior of many materials which exhibit nonlinear stress-strain behavior. The nonlinearity of such materials can be described more accurately by a hyperelastic material model (see Eq. (7)). In this section, the apple tissue is considered as nonlinear viscoelastic continuum material. A more recent method to develop a nonlinear viscoelastic model is to write the Helmholtz free energy density function (strain-energy function) as the sum of hyperelastic and viscous terms (Holzapfel, 2000; Pena et al., 2008). This type of model is advantageous for finite element formulations (Pena et al., 2008). The model (see Eq. (7)) is based on the theory of compressible hyperelasticity with the decoupled representation of the Helmholtz free energy function with the internal variables (Holzapfel, 2000). The way in which the second Piola-Kirchhoff stress tensor (S) and the deformation gradient tensor $(F)$ are defined, is specified below.

The second Piola-Kirchhoff stress tensor (see Eq. (7)) can be calculated from hyperelastic strain energy functions. This second Piola-Kirchhoff stress, which is the partial derivative of the Helmholtz free energy (Eq. (19)) with the right Cauchy-Green deformation tensor $C$, can be expressed as a sum of volumetric and isochoric parts:

$S=2 \frac{\partial \psi\left(C, \Gamma_{1}, \ldots ., \Gamma_{m}\right)}{\partial C}=S_{V O L}^{\infty}+S_{I S O}=S_{V O L}^{\infty}+S^{\infty}{ }_{I S O}+\sum_{\alpha=1}^{m} Q_{\alpha}$

Note that the isochoric stress tensor $\left(S_{I S O}\right)$ is split into equilibrium and non-equilibrium (viscoelastic) parts. The tensor variables $\left(\Gamma_{1}, \Gamma_{2}, \ldots, \Gamma_{m}\right)$ are internal variables, similar to strain, which characterize the relaxation behavior of the material, with one variable for each Maxwell element ( 3 in this study). The decoupled representation of the Helmholtz free energy is given by:

$\psi\left(C, \Gamma_{1}, \ldots, \Gamma_{m}\right)=\psi_{\text {VOL }}^{\infty}\left(J^{e}\right)+\psi_{\text {ISO }}^{\infty}(\bar{C})+\sum_{\alpha=1}^{m} \Upsilon_{\alpha}\left(\bar{C}, \Gamma_{\alpha}\right)$

The first two terms in Eq. (19) characterize the equilibrium state and describe the volumetric (or dilatational) elastic response and the isochoric (or distortional) elastic response as $t$ approaches $\infty$, respectively. The third term is the dissipative potential responsible for the viscoelastic contribution, corresponding to the third term in Eq. (18). All terms are explained more in detail in following paragraphs.

The elastic response is given by:

$\psi_{V O L}^{\infty}\left(J^{e}\right)=\frac{\kappa}{2}\left(J^{e}-1\right)^{2}$

$\kappa=(1-2 v)\left(C_{1}+C_{2}\right) / 2$

Where $J^{e}$ represents the Jacobian of the elastic response. The parameters $\left(C_{1}, C_{2}\right)$ are to be determined from experiments.

Two types of hyperelastic potentials are considered in the model: the Mooney-Rivlin hyperelastic potential with three parameters and Yeoh hyperelastic potential with three parameters (Martins et al., 2006; ANSYS, 2009; Ali et al., 2010). The Mooney-Rivlin hyperelastic potential is usually defined by two parameters, but in this study, three parameters are used because more hyperelastic parameters provide a better fit to the exact solution (ANSYS, 2009).

$\psi_{\text {ISO }}^{\infty}(\bar{C})=C_{1}\left(\bar{I}_{1}-3\right)+C_{2}\left(\bar{I}_{2}-3\right)+C_{3}\left(\bar{I}_{1}-3\right)\left(\bar{I}_{2}-3\right)$

The Yeoh hyperelastic potential with three parameters is: 


\section{KU LEUVEN}

$\psi^{\infty}{ }_{\text {ISO }}(\bar{C})=C_{10}\left(\bar{I}_{1}-3\right)+C_{01}\left(\bar{I}_{1}-3\right)^{2}+C_{11}\left(\bar{I}_{1}-3\right)^{3}$

The parameters $\left(C_{10}, C_{01}, C_{11}, C_{1}, C_{2}, C_{3}\right.$ and $\left.\kappa\right)$ are to be determined from experiments (see section 3.2).

The viscoelastic contribution in Eq. (19) is discussed by means of its partial derivative with the right Cauchy-Green tensor, $C$ (see Eq. (24)). It is composed of internal tensor variables, $Q_{\alpha}, \alpha=1,2,3$ (Holzapfel, 2000). Motivated by the generalized Maxwell rheological model, three Maxwell elements $(m=3)$ with one free spring were used, as shown in Figure 2. The evolution equation (Eq.(26)), from which the internal variable $Q_{\alpha}$ is determined, is derived from following two equations (Holzapfel, 2000):

$\dot{Q}_{\alpha}+\frac{Q_{\alpha}}{\tau_{\alpha}}=\dot{S}_{I S O_{\alpha}}$

$S_{I S O_{\alpha}}=\beta_{\alpha}^{\infty} S^{\infty}{ }_{I S O}(\bar{C})$

$Q_{\alpha}=\exp \left(-T / \tau_{\alpha}\right) Q_{\alpha 0}+\int_{0}^{T} \exp \left(-(T-t) / \tau_{\alpha}\right) \beta_{\alpha}^{\infty} \dot{S}_{\text {ISO }}^{\infty}(\bar{C})$

The parameters $\left(\beta_{1}, \beta_{2}, \beta_{3}, T_{1}, T_{2}, T_{3}\right)$ are to be determined from experiments (see section 3.2).

Note that a nonlinear viscoelastic model differs from a linear viscoelastic model in following way: a linear viscoelastic model consists of linear elastic responses $\left(E_{e}, E_{1}, E_{2}, E_{3}\right)$ and viscous responses $\left(\eta_{1}, \eta_{2}, \eta_{3}\right)$, as shown in Figure 1, whereas a nonlinear viscoelastic model is based on a stored energy function $\psi$, which contains hyperelastic properties of the material, and an internal variable $\left({ }^{Q_{\alpha}}\right)$, which contains the viscous effects, as shown in Figure 2.

Similar to Eq.(4), the coupling between water transport and large deformation is based on a multiplicative decomposition of the deformation gradient $F$ into the elastic part $\left(F^{e}\right)$ and the swelling or shrinkage part $\left(F^{s}\right)$, respectively (Duda et al., 2010; Anand et al., 2010):

$F=F^{e} \cdot F^{s}$

The kinematic decomposition of Eq. (27) allows to determine the Jacobian of the elastic deformation as follows:

$$
\begin{aligned}
& J=D \text { et }(F) J^{e}=\operatorname{Det}\left(F^{e}\right), J^{s}=\operatorname{Det}\left(F^{s}\right) \\
& J=J^{e} J^{s} \rightarrow J^{e}=\frac{J}{J^{s}}
\end{aligned}
$$

The Jacobian of the shrinkage deformation is determined from:

$$
J^{s}=\left(\lambda^{s}\right)^{3}=\left(1+\varepsilon^{d}\right)^{3}
$$




\subsection{Solution procedure}

The model was numerically solved applying the finite element method, using the software Comsol Multiphysics 3.5a (Comsol BV, Sweden). The water transport, structural mechanics and partial differential equation (PDE) module were employed for the calculation of large deformation due to dehydration. The software PDE module was used for the integration of the evolution equation (Eq. (26)). The components of the isochoric stress rate $\left(\dot{S}_{I O_{\alpha}}\right)$ were determined in the Symbolic Toolbox in Matlab R2009b (The Mathworks, Nattick, CT) and added to the scalar expression table in Comsol. The hyperelastic model in Comsol only included the Mooney-Rivlin model with two parameters. Therefore the stain energy function was modified based on Eq. (22) for Mooney-Rivlin hyperelastic potential with three parameters and Eq. (23) for Yeoh hyperelastic potential with three parameters.

\section{$3 \quad$ Model parameters}

\subsection{Water transport model parameters}

The relevant water transport properties of Jonagold apples were taken from previous work (Veraverbeke et al., 2003c). The desorption isotherm of apple cortex, which represents the water content as a function of the water activity $\left(a_{w}\right)$, was used to model the water capacity $\left(c_{\phi}\right)$. The water activity is related to the water potential $(\phi)$ by the following equation:

$\phi=\frac{R T}{V_{w}} \ln \left(a_{w}\right)$

The hydraulic conductivity $(K)$ of the cortex was equal to $7.2 \times 10^{-15} \mathrm{~kg} \mathrm{~s}^{-1} \mathrm{~m}^{-1} \mathrm{~Pa}^{-1}$ and $\rho_{d m}$ was equal to 150 $\mathrm{kg} \mathrm{m}^{-3}$ (Veraverbeke et al., 2003c).

The mass transfer coefficient $h_{m}$ (Table 1) is calculated using an empirical correlation for heat transfer together with the heat and mass transfer analogy (Lewis analogy). For a cylindrical object with constant surface temperature in a flowing fluid with uniform velocity, the Nusselt number is given by the following empirical formula (Bird, Stewart \& Lightfoot, 2002):

$$
\begin{aligned}
& \mathrm{Nu}=\left(0.376 \mathrm{Re}^{1 / 2}+0.057 \mathrm{Re}^{2 / 3}\right) \operatorname{Pr}^{1 / 3}+0.92\left[\ln \left(\frac{7.4055}{\operatorname{Re}}\right)+4.18 \mathrm{Re}\right]^{-1 / 3} \operatorname{Re}^{1 / 3} \operatorname{Pr}^{1 / 3} \\
& \mathrm{Nu}=\frac{h_{T} d}{\lambda_{t}} \\
& \operatorname{Re}=\frac{\rho V d}{\mu} \\
& \operatorname{Pr}=\frac{C_{p} \mu}{\lambda_{t}}
\end{aligned}
$$




\section{KU LEUVEN}

Thermodynamic properties of air were taken from the ASHRAE HANDBOOK (1993). Using the Lewis analogy between heat and mass transfer (Incropera \& De Witt, 1990), the mass transfer coefficient $h$ is calculated from the heat transfer coefficient $h_{T}$ :

$$
\begin{aligned}
& h=\frac{h_{T}}{\rho c_{p} L e^{2 / 3}} \\
& L e=\frac{\lambda_{t}}{\rho c_{p} D_{\text {air }}} \\
& h_{m}=\frac{h V_{w}}{R T} \rho_{\text {sat }}
\end{aligned}
$$

To obtain the volumetric shrinkage coefficient in Eq. (6), fruit sample strips of $1 \times 1 \times 40 \mathrm{~mm}$ were gradually dried in desiccators containing saturated salt solutions ( $\mathrm{RH}: 33-98 \%)$. After equilibrium, the length was measured by a digital calliper and the water content was determined by drying samples in the oven at 105 ${ }^{\circ} \mathrm{C}$ for $48 \mathrm{~h}$. The volumetric shrinkage coefficient $\beta$ was calculated as 3 times the slope of the linear curve (linear or 1D deformation) of the relative length change versus water content. The value of $\beta$ was 0.108 , which agrees well with reported data for Golden delicious apples (Moreira et al., 2000), which was 0.096.

\subsection{Mechanical model parameters}

The parameters of the constitutive model to predict the stress response of the fruit were evaluated based on experimental data of compression-relaxation experiments. The mechanical properties of Jonagold apple were determined from these compression-relaxation tests. For these tests, apples, were optimally picked in September 2010 from the Experimental Station for Fruit Growing (Pcfruit, Sint-Truiden, Belgium) and stored at $1{ }^{\circ} \mathrm{C}$ in normal air for a few days until the experiment day. Compression tests were conducted at room temperature. Thereto, the apples were allowed to equilibrate to room temperature before the experiment $(10 \mathrm{~h})$. Six cylindrical samples from six different apples were taken radially on the equator from half-cut fruits by a cork borer (inside diameter of $16.6 \mathrm{~mm}$ ). The six specimens were cut to a length of $16 \mathrm{~mm}$ by a cutter.

A universal testing machine (Stable Microsystems Texture Analyzer, Surry, England) with a flat loading plate of $75 \mathrm{~mm}$ in diameter and a thickness of $10 \mathrm{~mm}$ was employed for compression and relaxation tests. In compression, the maximum attainable strain of the fruit was found to be about $10 \%$ strain, as reported by (Mohsenin, 1986). At higher strains, fruit will rupture. The compressive strain imposed on the sample during relaxation tests was 5\%. The compression test was conducted at crosshead speeds of $0.1 \mathrm{~mm} / \mathrm{s}$. Afterwards, the deformation of the sample was kept constant and the stress decay was monitored. These data were recorded by a Pentium IV computer for 500 s at a rate of 200 points/s.

For the linear model, material properties of apple for the linear elastic model such as the modulus of elasticity $(E=5 \mathrm{Mpa})$ and the Poisson's ratio $(v=0.35)$ were adopted from (Mohsenin, 1977; Mohsenin, 1986 \& Dintwa et al., 2008).

For the linear viscoelastic model, linear viscoelastic parameters with elastic constants $\left(E_{e}, E_{1}, E_{2}, E_{3}\right)$ and relaxation times $\left(I_{1}, T_{2}, T_{3}\right)$ were determined by fitting Eq. (39) to the corresponding experimental data using a non-linear least squares procedure implemented in the MATLAB 9.0 programming environment (The Mathworks, Inc., Natick, USA): 
$\sigma(t)=\varepsilon_{0}\left[E_{e}+E_{1} \exp \left(\frac{-\left(t-t_{0}\right)}{\tau_{1}}\right)+E_{2} \exp \left(\frac{-\left(t-t_{0}\right)}{\tau_{2}}\right)+E_{3} \exp \left(\frac{-\left(t-t_{0}\right)}{\tau_{3}}\right)\right]$

$\tau_{i}=\frac{\eta_{i}}{E_{i}}$

This expression originates from the generalized Maxwell model of cylindrical apple tissue, using equilibrium and decay moduli, and relaxation times of a Prony series (Kim et al., 2008).

The way of determining the parameters for the nonlinear viscoelastic model is explained in the following paragraphs. These parameters include the Mooney-Rivlin hyperelastic parameters $\left(C_{1}, C_{2}\right.$ and $\left.C_{3}\right)$ and Yeoh hyperelastic parameters $\left(C_{10}, C_{01}\right.$ and $\left.C_{11}\right)$, and the relaxation parameters $\left(\tau_{1}, T_{2}, T_{3}, \beta_{1}, \beta_{2}\right.$ and $\left.\beta_{3}\right)$. First, the hyperelastic parameters are discussed.

First, the Cauchy stress tensor $(\sigma)$ is written as $1 / J$ times the push-forward of $S\left(\sigma=J^{-1} \chi *(S)\right.$, where $\chi$ is the push-forward operation) as follows (Holzapfel, 2000):

$\sigma=p I+\frac{2}{J}\left(\left[\frac{\partial \psi_{\text {ISO }}}{\partial \bar{I}_{1}}+\bar{I}_{1} \frac{\partial \psi_{\text {ISO }}}{\partial \bar{I}_{2}}\right] \bar{b}-\frac{\partial \psi_{\text {ISO }}}{\partial \bar{I}_{2}} \bar{b}^{2}-\frac{1}{3}\left[\frac{\partial \psi_{\text {ISO }}}{\partial \bar{I}_{1}} \bar{I}_{1}+2 \frac{\partial \psi_{\text {ISO }}}{\partial \bar{I}_{2}} \bar{I}_{2}\right] I\right)$

Where $p=\frac{d \psi_{v o l}(J)}{d J}$. Note that $\bar{I}_{1}=J^{-2 / 3} I_{1}, \bar{I}_{2}=J^{-4 / 3} I_{2}, I_{3}=J$ and $I_{3}=I$. The strain invariants are defined as a function of stretch ratios as (Bonet $\&$ Wood, 1997):

$$
\begin{aligned}
& I_{1}=\lambda_{1}^{2}+\lambda_{2}^{2}+\lambda_{3}{ }^{2} \\
& I_{2}=\lambda_{1}^{2} \lambda_{2}^{2}+\lambda_{2}{ }^{2} \lambda_{3}^{2}+\lambda_{3}{ }^{2} \lambda_{1}{ }^{2} \\
& I_{3}=\lambda_{1}{ }^{2} \lambda_{2}{ }^{2} \lambda_{3}{ }^{2}
\end{aligned}
$$

The particular case of hyperelastic materials subjected to a uniaxial load deformation is considered:

$$
\lambda_{1}=\lambda, \lambda_{2}=\lambda_{3}=\frac{1}{\sqrt{\lambda}}
$$

Where $\lambda_{1}=\lambda$ is the stretch ratio in the direction of load.

According to Eq. (41), the Cauchy stress was formulated using the strain energy density functions given by Eq. (22) (Mooney-Rivlin) and Eq. (23) (Yeoh) to determine the hyperelastic parameters. Thus, the Cauchy stress for Mooney-Rivlin and Yeoh hyperelastic potentials can be expressed as:

$$
\begin{aligned}
& \sigma_{\text {Mоопе }}(\lambda)=2\left(\lambda-\frac{1}{\lambda^{2}}\right)\left(C_{1}+C_{2}\left(\frac{1}{\lambda}\right)+C_{3}\left(\left(\lambda+\frac{2}{\lambda^{2}}-\frac{3}{\lambda}\right)+\left(2 \lambda+\frac{1}{\lambda^{2}}-3\right)\right)\right) \\
& \sigma_{\text {Yeoh }}(\lambda)=2\left(\lambda^{2}-\frac{1}{\lambda}\right)\left(C_{10}+2 C_{01}\left(\lambda^{2}+\frac{2}{\lambda}-3\right)+3 C_{11}\left(\lambda^{2}+\frac{2}{\lambda}-3\right)^{2}\right)
\end{aligned}
$$

The Mooney-Rivlin hyperelastic parameters $\left(C_{1}, C_{2}\right.$ and $\left.C_{3}\right)$ and Yeoh hyperelastic parameters $\left(C_{10}, C_{01}\right.$ and $C_{11}$ ) were estimated by fitting Eq. (46) and Eq. (47) respectively, to the corresponding experimental data using a non-linear least squares procedure implemented in the MATLAB 9.0 programming environment (The Mathworks, Inc., Natick, USA) as presented in section 4.1. In the next section, the relaxation parameters are determined. 


\section{KU LEUVEN}

The stress relaxation behavior of the apple tissue is obtained by $1 / J$ times the push-forward expression of Eq. (26), which results for Yeoh hyperelastic potential in:

$$
\begin{aligned}
\sigma(t) & =2 \lambda^{2}\left(1-\frac{1}{\lambda^{3}}\right)\left(C_{10}+2 C_{01}\left(\lambda^{2}+\frac{2}{\lambda}-3\right)+3 C_{11}\left(\lambda^{2}+\frac{2}{\lambda}-3\right)^{2}\right) \\
& \left.\times\left[\left(1-\left(\beta_{1}+\beta_{2}+\beta_{3}\right)\right)+\beta_{1} \exp \left(-t / \tau_{1}\right)+\beta_{2} \exp \left(-t / \tau_{2}\right)+\beta_{3} \exp (-t) / \tau_{3}\right)\right]
\end{aligned}
$$

Note that for Mooney-Rivlin hyperelastic potential, the hyperelastic parameters $\left(C_{10}, C_{01}\right.$ and $\left.C_{11}\right)$ should be substituted by $\left(C_{1}, C_{2}\right.$ and $\left.C_{3}\right)$ in Eq. (48). The relaxation parameters $\left(\tau_{1}, T_{2}, T_{3}, \beta_{1}, \beta_{2}\right.$ and $\left.\beta_{3}\right)$ were also estimated by fitting Eq. (48) to the corresponding experimental data using a non-linear least squares procedure implemented in the MATLAB 9.0 programming environment (The Mathworks, Inc., Natick, USA) as presented in section 4.1 .

\subsection{Model validation}

For X-ray CT validation experiments, apples (Malus domestica Borkh., cv. Jonagored) were picked at their commercial picking date in September 2006 from the Experimental Station for Fruit Growing (Pcfruit, SintTruiden, Belgium). Apple fruits were stored for 4 months in an airtight container under controlled atmosphere conditions $\left(1 \% \mathrm{O}_{2}, 2.5 \% \mathrm{CO}_{2}\right.$ at $1{ }^{\circ} \mathrm{C}$ and $\left.\pm 95 \% \mathrm{RH}\right)$ until the experiment started in 2007 . The apples for the experiments were randomly chosen from the storage containers. Samples for the X-ray CT experiment were taken from the apple inner cortex as indicated in Figure 3. The skin was retained on the two end surfaces to limit water transport in the direction of the revolution axis.

A dehydration experiment on a cylindrical apple cortex sample (diameter $16.6 \mathrm{~mm}$ ) was conducted for 6 hours in circulating air $\left(20^{\circ} \mathrm{C}\right.$ and $30 \% \mathrm{RH}$ ) at a speed of $1 \mathrm{~ms}^{-1}$. A low relative humidity was maintained in the atmosphere to achieve a sufficient dehydration rate for the apple. At the start of the experiment, the water content was considered homogeneous in the whole sample and equal to $7.5 \mathrm{~kg} \mathrm{~kg}_{\mathrm{dm}}^{-1}$.

An X-ray computed tomography (CT) system (Tomohawk, AEA Technology, UK) was operated using an Xray source (Philips HOMX 161) at a voltage of $70 \mathrm{kV}$, current of $0.5 \mathrm{~mA}$ and field of view $182.7 \mathrm{~mm}$. Each pixel in the digital image obtained by a CCD camera (JAI M50) represented a linear resolution of $100 \mu \mathrm{m}$. The sample was scanned over the interval $0^{\circ}-180^{\circ}$ using a $0.9^{\circ}$ scan step, every hour of the drying experiment. The X-ray shadow projections of the central part (inner cortex) of the 3-D sample were processed by a mathematical algorithm based on the back-projection procedure (Tomohawk software version 3.5.2, AEA Technology, UK) to obtain reconstructed cross-sectional gray-scale images of the attenuation coefficient of the tissue. The grayscale is a function of the local water content of the tissue. The calculations of water content are based on a mixture rule: the gray scale $I_{g}$ of the reconstructed CT images is proportional to the linear attenuation coefficient of the tissue $\mu / \rho$, which is assumed to be linearly related to the attenuation coefficients of the dry matter and water fractions as follows (Hubbell and Seltzer, 1995):

$$
I_{g} \propto \frac{\mu}{\rho}=\left(\frac{1}{X+1}\left(\frac{\mu}{\rho}\right)_{d m}+\frac{X}{X+1}\left(\frac{\mu}{\rho}\right)_{w}\right)
$$

The attenuation coefficient for water was taken from tables available in Hubbell and Seltzer (1995). A calibration experiment was performed to determine $(\mu / \rho)_{d m}$ and the proportionally constant. Thirty small samples of apple tissue were dried to different levels of uniform water content and were imaged by X-ray 
CT. After scanning, the water content was determined. The calibration of X-ray CT images of inner apple cortex samples with respect to water content was performed in the range of 2 to 6.5 dry base water content. Using $(\mu / \rho)_{w}=0.211$ (Hubbell and Seltzer, 1995), the value of $(\mu / \rho)_{d m}$ was fitted to be 0.135. The coefficient of determination $\left(R^{2}\right)$ of the corresponding gray scale prediction was 0.85 , with a slope of approximately unity (Figure 4). The resulting linear relationship showed considerable variability. This is due to the fact that it was difficult to dry sufficiently sized tissue samples to different uniform water content. In addition, apple fruit contains a considerable amount of air spaces: when the resolution of the CT system is increased to a pixel size below $10 \mu \mathrm{m}$, individual pores can be observed (Mendoza et al., 2007; Verboven et al., 2008), which were found to take up 20 to $30 \%$ of the fruit volume. Therefore, uneven distribution of air spaces will affect the measured CT image intensity, as also displayed later on in Figure 6.

\subsection{Numerical model and boundary conditions}

For model validation purposes, a two dimensional model was applied to the aforementioned process of dehydration (section 3.3) of a long apple cortex cylinder of $16.6 \mathrm{~mm}$ diameter. At the start of the experiment, the water content was constant and equal to $7.5 \mathrm{~kg} \mathrm{~kg}_{\mathrm{dm}}{ }^{-1}$ and temperature of $20{ }^{\circ} \mathrm{C}$.

The boundary condition at the surface with respect to water transfer was expressed as:

$-K \frac{\partial \phi}{\partial n}=h_{m}\left(\phi-\phi_{\infty}\right)$

This equation indicates the continuity of the water gradient at the air-tissue interface. The water potential is related to the chemical potential of water, which expresses the free energy associated with the water in the tissue. It depends on the water concentration, solute concentration and pressure. The ambient water potential $\left(\phi_{\infty}\right)$ was calculated based on the temperature and relative humidity of the environment (Nobel, 1991):

$\phi_{\infty}=\frac{R T}{V_{w}} \ln \left(\frac{R H_{\infty}}{100}\right)$

The 2D circular geometry was meshed by 8768 triangular elements with a total of 67215 degrees of freedom. The computations were performed on a Windows Vista computer with an Intel Quad core CPU Processor $(2.83 \mathrm{GHz})$ and $8 \mathrm{~GB}$ RAM.

\section{$4 \quad$ Results and discussion}

\subsection{Mechanical properties of apple cortex tissue}

Figure 5 displays the stress-strain response of the apple cortex samples and the constitutive model fit in Eq. (47) for each. For each experimental data set, the parameters of the corresponding model fit are determined separately. The average values and standard deviation of these parameters, determined by the constitutive model fits, are given in Table 3. The modeled stress-strain responses accurately predict the nonlinear curve characteristic of the tissue. Note that experimental variability is observed, which is mainly

Published version: http://dx.doi.org/10.1007/s11947-012-0862-1 


\section{KU LEUVEN}

attributed to biological variability among different tissues due to, e.g., the presence of vascular bundles or a variation in cell and air space size distributions such as observed by (Mendoza et al., 2007) and (Verboven et al., 2008). As a result, a distinct spread is found on the estimated model parameters of the apple tissue (Table 3). Such a spread is characteristic for biological tissues. The fitting constants for a specific compression-relaxation experiment however approximate very well the experimental data: the average $R^{2}$ value was very close to $1\left(R^{2}=0.998\right)$. Linear viscoelastic properties are estimated using Eq. (39) and the average values and standard deviations of these parameters, determined by model fits, and are given in Table 2.

\subsection{Validation study: dehydration and deformation of apple cortex tissue}

In this section, the results of the models developed to quantify the deformation of the cylindrical apple tissue (see section 2.2) are compared with the experimental dehydration results (see section 3). Figure 6 displays the 2D contour plots of X-ray CT measurements compared to the model simulations. The diameter of the sample decreases steadily with dehydration time, while a gradient in water content develops close to the surface.

In Figure 7 the percentual change in diameter is displayed as a function of dehydration time with respect to the initial diameter for the experiment and different models. A decrease of the diameter of $18 \%$ after 6 hours is obtained experimentally. The nonlinear viscoelastic model shows a better agreement with the observed shrinkage profile than the linear elastic and linear viscoelastic models. The linear elastic and viscoelastic model predictions were accurate at the start of the dehydration process. This is due to the fact that the theory of small deformation with constant Young's modulus is still valid here. However, most biomaterials show nonlinear stress-strain behaviour at large deformations, which cannot be represented accurately by a constant Young's modulus. Instead, hyperelastic material models should be used. No significant differences were observed between the predictions of linear elastic and viscoelastic models.

In addition to shrinkage, a gradient in water content develops below the surface during dehydration. The resulting water gradient that developed in the apple sample during the dehydration experiment is given in Figure 8 for both experiment and the best-fitting nonlinear viscoelastic model (with Yeoh hyperelasic potential). The agreement is good but after 6h, clear discrepancies can be observed near the edge of the sample. This can be due to the fact that a constant water conductivity is used in the water transport model as water conductivity is a function of water content (Assouline et al., 2001), or the fact that tension generated in the tissue causes water flow into the sample (Van der Sman, 2007). Figure 9 depicts the average water content with dehydration time. A comparison was made between the experimental measurement and the water transport model results with and without consideration of shrinkage. Taking the shrinkage into account in the model during dehydration results in better predictions of the water content than a model that assumes no shrinkage according to (Ratti and Crapiste, 2009) and (Bialobrzewski, 2006). This is due to the fact that the surface area of the model without shrinkage would be bigger and thus the water will be lost more rapidly to the environment. Figure 9 clearly shows that the model with shrinkage provides better predictions than the model that does not take shrinkage into account. 


\subsection{Sensitivity of the model}

In this section, the sensitivity of the dehydration results to different model parameters is explored since the nonlinear viscoelastic model parameters, estimated from independent experiments, showed a distinct spread (Table 3), due to biological variability. Therefore a sensitivity analysis of the nonlinear viscoelastic model with Yeoh hyperelasic potentials was carried out to determine which parameters influence the model predictions the most. The relative sensitivities were calculated as normalized partial derivatives (central differencing scheme) of tissue deformation, $U$, with respect to the model parameters, $X_{i} . U$ represents the time-dependent decrease in diameter due to dehydration and $X_{i}$ represents a specific model parameter (see Table 3 and the reported water transport properties). The relative sensitivity of the deformation to the model parameter can be calculated by:

$S_{U, X_{i}}=\frac{\partial U / U}{\partial X_{i} / X_{i}} \cong \frac{U_{X_{i}+\Delta X_{i}}-U_{X_{i}-\Delta X_{i}}}{2 \Delta X_{i}} \frac{X_{i}}{U}$

where $\Delta X_{i}$ is taken equal to $1 \%$ deviation from the nominal average value of $X_{i}$.

The sensitivity of the model to the input parameters is depicted in Figure 10. The model is more sensitive to the water transport parameters $\left(h_{m}, K, \beta, X_{0}\right.$ and $\left.\rho_{d m}\right)$ depicted in Figure 10a and 10b than to the hyperelastic parameters $\left(C_{10}, C_{01}, C_{11}, C_{1}, C_{2}, C_{3}\right.$ and $\left.\kappa\right)$ depicted in Figure $10 \mathrm{c}$ and $10 \mathrm{~d}$. A distinct temporal sensitivity to the water transport parameters was also found, whereas the sensitivity of the hyperelastic parameters remained quasi constant over time, except for $C_{10}$. The relative sensitivity analysis in Figure $10 \mathrm{e}$ and $10 \mathrm{f}$ showed that viscoelastic parameters $\left(\tau_{1}, T_{2}, T_{3}, \beta_{1}, \beta_{2}\right.$ and $\left.\beta_{3}\right)$ do not have much influence on deformation, and sensitivities stay quasi constant in time. As expected, the volumetric shrinkage coefficient $(\beta)$, which couples the water transport to mechanical deformation, and the initial water content $\left(X_{0}\right)$ are found to be the most sensitive parameters in the model.

Note that the spread on the nonlinear viscoelastic model parameters (Table 3 ) was quite large due to the biological variability between different tissues. As the nonlinear viscoelastic model relies on many model parameters, the model results could be more sensitive to uncertainty propagation than a more simplified model, e.g., the linear elastic model. On the other hand, such model complexity (i.e., including several Maxwell elements) often allows to model the required physical phenomena, which more simplified models lack.

\subsection{Effect of temperature and relative humidity}

It is known that the relative humidity of the ambient atmosphere has a considerable effect on the water loss of produce during storage (Veraverbeke et al., 2003b; 2003c; Wills et al., 1998; Salunkhe \& Kadam, 1995) and also during drying processes. The nonlinear viscoelastic model with Yeoh hyperelastic potentials was used to quantify the effect of temperature and relative humidity on deformation of apple tissue. Four different values of $\mathrm{RH}$ were considered $(30 \%, 60 \%, 75 \%$ and $95 \%)$ in the simulation at two different temperatures $\left(1{ }^{\circ} \mathrm{C}\right.$ and $\left.20^{\circ} \mathrm{C}\right)$. The deformation with dehydration time is shown in Figures $11 \mathrm{a}$ and $11 \mathrm{~b}$.

Published version: http://dx.doi.org/10.1007/s11947-012-0862-1 


\section{KU LEUVEN}

The increase of the relative humidity from $30 \%$ to $95 \%$ caused a decrease in deformation from $17.98 \%$ to $0.33 \%$ after 6 hours of dehydration.

The influence of temperature on deformation is depicted in Figures $12 \mathrm{a}$ and $12 \mathrm{~b}$, by evaluating three different temperatures $\left(1{ }^{\circ} \mathrm{C}, 10{ }^{\circ} \mathrm{C}\right.$ and $20{ }^{\circ} \mathrm{C}$ ) at relative humidities of $30 \%$ and $60 \%$. The temperature increase from $1{ }^{\circ} \mathrm{C}$ to $20{ }^{\circ} \mathrm{C}$, at $30 \%$ and $60 \%$ relative humidity, increased the deformation from $5.38 \%$ to $17.99 \%$ and from $2.2 \%$ to $6.93 \%$, respectively, at the end of dehydration. No significant effect on change of temperature was observed in the high relative humidity regimes.

\section{$5 \quad$ Conclusions}

We presented a validated model of coupled water transport and mechanical deformation in fruit, where the tissue was modeled as a nonlinear viscoelastic material. This model can be employed for a better understanding of postharvest storage and drying processes where large deformations occur, which can lead to improved product quality. The model parameters were estimated from independent experiments and experimental validation of the model was presented. From a comparison with linear elastic and linear viscoelastic models, the nonlinear viscoelastic model clearly showed improved accuracy for large deformations. The linear elastic and viscoelastic models can alternatively be used instead of the nonlinear viscoelastic model at the beginning of the dehydration process, i.e., where deformations are still relatively small. The sensitivity to the nonlinear viscoelastic model parameters was investigated, showing a larger sensitivity to water transport parameters than to the mechanical parameters. Furthermore, a large effect of relative humidity and temperature on the deformation of apple tissue was identified. Future developments could focus on modeling a complete apple, taking into account its 3D nature and incorporating different tissues (inner, outer cortex and cuticle) and the skin. Finally note that the model incorporates many empirical parameters that are related to the structure and composition of the cellular tissues, on which a large spread was found due to biological variability. For a better understanding, the structure-property relationships should be investigated by means of a multiscale approach.

\section{Acknowledgements}

The authors would like to acknowledge the Fund for Scientific Research - Flanders (Grant no. FWO G.0603.08), the K.U.Leuven (project OT 08/023) and the EC (FP7-226783 project InsideFood) for financial support. Thijs Defraeye is a postdoctoral fellow of the Research Foundation - Flanders (FWO). 


\section{REFERENCES}

Akiyama, T., \& Hayakawa K. (2000). Heat and moisture transfer and hygrophysical changes elastoplastic hollow cylinder-food during drying. Journal of Food Engineering 65, 315- 323.

Ali, A., Hosseini, M., \& Sahari, B. B. (2010). A Review of Constitutive Models for Rubber- Like Materials. American Journal of Engineering and Applied Sciences 3, 232-239.

Amarante, C., Banks, N. H., \& Ganesh, S. (2001). Relationship between character of skin cover of coated pears and permeance to water vapour and gases. Postharvest biology and technology 21(3), 291301.

Anand, L., \& Chester, S. A. (2010). A coupled theory of fluid permeation and large deformations for elastomeric materials. Journal of the Mechanics and Physics of Solids 58, 1879-1906

ANSYS. (2009). Hyperelasticity, finite strain elasticity. User's Manual, Version 12, Canonsburg, PA

ASHRAE HANDBOOK. (1993). Fundamentals. American society of heating, refrigerating and airconditioning Engineering, inc. Atlanta.

Assouline, S., \& Tartakovsky, D. M. (2001). Unsaturated hydraulic conductivity function based on a soil fragmentation process. Water Resources Research 37, 1309-1312.

Bialobrzewski, I. (2006). Simultaneous heat and mass transfer in shrinkable apple slab during drying. Drying Technology 24: 551-559.

Bird, R. B., Stewart, W. E., Lightfoot, E. N. (2002). Transport phenomena. New York: John Wiley

Bonet, J., \& Wood, R. D. (1997). Nonlinear Continuum Mechanics for Finite Element Analysis. Cambridge University Press, United Kingdom.

COMSOL Multiphysics. (2008). Structural mechanics module, continuum Application modes. Version 3.5a, Stockholm, Sweden.

De Smedt, V., Barreiro, P., Verlinden, B., Veraverbeke, E., De Baerdemaeker, J., \& Nicolaï, B. (2002). A mathematical model for the development of mealiness in apples. Postharvest biology and technology, 25 (3), 273-291.

Dintwa, E., Zeebroeck, M. V., Ramon, H., \& Tijskens, E. (2008). Finite element analysis of the dynamic collision of apple fruit. Postharvest Biology and Technology 49, 260-276.

Duda, F. P., Souza, A. C., \& Fried, E. (2010). A theory for species migration in finitely strained solid with application to polymer network swelling. Journal of the Mechanics and Physics of Solids 58, 515-529.

Gekas, V., \& Sjoholm, I. (1995). Apple shrinkage upon drying. Journal of Food Engineering 25, 123-130.

Garikipati, K., \& Raoy, V. S. (2001). Recent Advances in Models for Thermal Oxidation of Silicon. Journal of Computational Physics 147, 138-170.

Halder, A., Datta, A. K., \& Spanswick, R. M. (2011). Water transport in cellular tissues during thermal processing. American Institute of Chemical Engineers AIChE Journal 57, 2574-2588.

Haghighi, K. (1990). Finite element simulation of the thermo-hydro stresses in a viscoelastic Sphere during drying. Dry Technology 8(3), 451-464.

Holzapfel, G. A. (2000). Nonlinear Solid Mechanics. A Continuum Approach for Engineering. Wiley, Chichester.

Hubbell, J. H., \& Seltzer, S. M. (1995). Tables of X-ray Mass Attenuation Coefficients and Mass EnergyAbsorption Coefficients $1 \mathrm{keV}$ to $20 \mathrm{MeV}$ for Elements $Z=1$ to 92 and 48 Additional Substances of Dosimetric Interest, National Institute of Standards and Technology.

Inazu T., Iwasaki, K., \& Furuta, T. (2005). Stress and crack prediction during drying of Japanese noodle. International Journal of Food Science and Technology 40, 621-630.

Incropera, F. P., \& De Witt., D. P. (1990). Fundamentals of Heat and Mass Transfer, third ed. Wiley, New York.

Irudayaraj, J., Haghighi, K., \& Stroshine, R. L. (1992). Finite-element analysis of drying with application to cereal grains. Journal of Agricultural Engineering Research 53(3), 209-229.

Itaya, Y., Kobayashis, T., \& Hayakawa, K. (1995). Three-dimensional heat and moisture transfer with viscoelastic strain-stress formation in composite food during drying. International Journal of Heat and Mass Transfer 38, 1173-1185

Izum, M., \& Hayakawa, K. (1995). Heat and moisture transfer and hygrostress crack formation and propagation in cylinderical, elastoplastic food. International Journal of Heat and Mass Transfer 38, 1033-1041.

Janjai, S., Lambert, N., Intawee, P., Mahayothee, B., Haewsungcharern, M., Bala, B. K., Nagle, M., Leis, H., \& Muller, J. (2008b). Finite element simulation of drying of longan fruit. Drying Technology 26, $666-674$.

Janjai, S., Lambert, N., Intawee, P., Mahayothee, B., Haewsungcharern, M., Bala, B. K., \& Müller, J. (2008a). Finite element simulation of drying of mango. Biosystems Engineering 299, 523-531.

Lima, A. G. B., Queiroz, M. R., \& Nebra, S. A. (2002). Simultaneous moisture transport and shrinkage during drying of solids with ellipsoidal configuration Chemical Engineering Journal 86, 85-93.

Lubarda, V. A., \& Hoger, A. (2002). On the mechanics of solids with a growing mass. International Journal of Solids and Structures 39, 4627-4664.

Marcotte, M., Toupin, C. J., \& Le Maguer, M. (1991). Mass transfer in cellular tissues. Part I: The mathematical model Journal of Food Engineering 13(3), 199-220.

Published version: http://dx.doi.org/10.1007/s11947-012-0862-1

Journal homepage: http://www.springer.com/food+science/journal/11947 
Martins, P. A. L., Jorge, R. M., \& Ferreira, A. J. (2006). A comparative study of several material models for prediction of hyperelastic properties: Application to silicone-rubber and soft tissues. Strain volume 42 , 135-147.

Mayor, L., \& Sereno, A. M. (2004). Modeling shrinkage during convective drying of food materials: a review. Journal of Food Engineering 25, 373-386.

Mendoza, F., Verboven, P., Mebatsion, H. K., Kerckhofs, G., Wevers, M., \& Nicolaï, B. M. (2007). Three dimensional Pore Space Quantification of Apple Tissue using X-ray Computed Microtomography, Planta, in press.

Mohsenin, N. N. (1977). Characterization and failure in solid foods with particular reference to fruits and vegetables. Journal of Texture Stud. 8, 169-193.

Mohsenin, N. N. (1986). Physical Properties of Plant and Animal Materials (2nd Edn). Gordon \& Breach Science Publishers, New York.

Moreira, R., Figueiredo, A., \& Sereno, A. (2000). Shrinkage of apple disc during drying by warm air convection and freeze drying. Drying Technology 18, 279-294.

Nguyen, T., Verboven, P., Daudin, J., \& Nicolaï, B. 2004. Measurement and modelling of water sorption isotherms of 'Conference' pear flesh tissue in the high humidity range. Postharvest biology and technology, 33 (3), 229-241.

Nguyen, T. A., Dresselaers, T., Verboven, P., D'hallewin, G., Culeddu, N., Van Hecke, P., \& Nicolaï, B. M. (2006a). Finite element modelling and MRI validation of 3D transient water profiles in pears during postharvest storage. Journal of the Science of Food and Agriculture 86 (5), 745-756.

Nguyen, T. A., Verboven, P., Scheerlinck, N., Vandewalle, S., \& Nicolai, B. M. (2006b). Estimation of effective diffusivity of pear tissue and cuticle by means of a numerical water diffusion model. Journal of Food Engineering 72 (1), 63-72.

Nguyen, T., Verboven, P., Schenk, A., \& Nicolaï, B. (2007). Prediction of water loss from pears (Pyrus communis cv.Conference) during controlled atmosphere storage as affected by relative humidity. Journal of food engineering, 83 (2), 149-155.

Niamnuy, C., Devahastin, S., Soponronnarit, S., \& VijayaRaghavan, G. S. (2008). Modeling coupled transport phenomena and mechanical deformation of shrimp during drying in a jet spouted bed dryer. Journal of Chemical Engineering 63, 5503 -5512.

Nobel, P. S. (1991). Physiochemical and environmental plant physiology. New York: Academic Press, Inc.

Nicoleti, J.F., Silveira-Jr, V., Telis-Romero, J., \& Telis, V.R.N. (2005). Viscoelastic behavior of persimmons dried at constant air temperature. LWT - Food Science and Technology 38 (2): 143-150.

Pena, E., Pena, J. A., Martinez, M. A., \& Doblare, M. (2008). On modelling nonlinear viscoelastic effects in ligaments. Journal of Biomechanics 41, 2659- 2666.

Piotr, P. L., \& Ewa, J. (2004). Effect of hot air temperature on mechanical properties of dried apples. Journal of Food Engineering 64, 307-314.

Kim, G. W., Kim, M. S., Sagara, Y., Bae, Y. H, lee, I. B., Do, G. S., Lee, S. H., \& Kang, S. W. (2008). Determination of the viscoelastic properties of apple flesh under quasi-static compression based on finite element optimization. Journal of Food Science Technology 14, 221-231.

Kowalski, S. J., \& Rajewska, K. (2002). Drying-induced stresses in elastic and viscoelastic saturated materials. Chemical Engineering Science 57, 3883-3892.

Kowalski, S. J. (2005). Toward a thermodynamics and mechanics of drying processes. Journal of Chemical Engineering Science 55, 1289-1304.

Mendoza, F., Verboven, P., Mebatsion, H., Kerckhofs, G., Wevers, M., \& Nicolaï, B. (2007). Threedimensional pore space quantification of apple tissue using X-ray computed microtomography. Planta, 226 (3), 559-570.

Rakesh, V., \& Datta, A. K. (2011). Microwave puffing: Determination of optimal conditions using a coupled multiphase porous media-Large deformation model. Journal of Food Engineering, 107(2), 152-163.

Rambert, G., Jugla, G., Grandidier, J. C., \& Cangemi, L. (2006). A modelling of the direct couplings between heat transfer, mass transport, chemical reactions and mechanical behaviour. Numerical implementation to explosive decompression. Composites, Part A $3,571-584$.

Ratti, C., \& Crapiste, G. H. (2009). Modeling of Batch Dryers for Shrinkable Biological Materials. Food Bioprocess Technology 2, 248-256

Salunkhe, D. K., \& Kadam, S. S. (1995). Handbook of fruit science and technology. Production, composition, storage and processing. Marcel Dekker, Inc., New York.

Simo, J. C., \& Hughes, T. J. R. (1998). Computational Inelasticity. Springer, New York.

Taiz, L., \& Zeiger, E. (2002). Plant Physiology, Third ed., Sinauer Associates Inc. Publishers, Sunderland, Massachusetts.

Srinivasa, A. R., \& Baek, S. (2004). Diffusion of a fluid through an elastic solid undergoing large deformation. International Journal of Non-Linear Mechanics 39:201-218.

Toupin, C. J., Marcotte, M., \& Le Maguer, M. (1989). Osmoticallyinduced mass transfer in plant storage tissues: A mathematical model. Part I. Journal of Food Engineering 10(1), 13-38.

Van der Sman, R. G. M. (2007). Moisture transport during cooking of meat: An analysis based on FloryRehner theory. Meat Science 76, 730-738.

Veraverbeke, E. A., Verboven, P., Van Oostveldt, P., \& Nicolai, B. M. (2003a). Prediction of moisture loss across the cuticle of apple (Malus sylvestris subsp mitis (Wallr.)) during storage: part 2. Model simulations and practical applications. Postharvest Biology and Technology 30 (1), 89-97. 
Veraverbeke, E. A., Verboven, P., Van Oostveldt, P., \& Nicolai, B. M. (2003b). Prediction of moisture loss across the cuticle of apple (Malus sylvestris subsp mitis (Wallr.)) during storage Part 1. Model development and determination of diffusion coefficients. Postharvest Biology and Technology 30 (1), 75-88.

Veraverbeke, E. A., Verboven, P., Scheerlinck, N., Hoang, M. L., \& Nicolai, B. M. (2003c). Determination of the diffusion coefficient of tissue, cuticle, cutin and wax of apple. Journal of Food Engineering 58 (3), 285-294.

Verboven, P., Kerckhofs, G., Mebatsion, H. K., Ho, Q. T., Temst, K., Wevers, M., Cloetens, P., \& Nicolaï, B. M. (2008). Three_Dimensional gas exchange pathways in pome fruit chracterized by synchroton $X$ Ray computed tomography. Plant physiology 142, 518-527.

Wang, J. (2003). Anisotropic Relaxation Properties of Pear. Biosystems Engineering 85 (1): $59-65$.

Wills, R., McGlasson, B., Graham, D., \& Joyce, D. (1998). Postharvest: an introduction to the physiology and handling of fruit, vegetables and ornamentals (4th edition, CAB INTERNATIPONAL). Willingford Oxon, UK.

Yang, H., Sakai, N., \& Watanabe, M. (2001). Drying model with non-isotropic shrinkage deformation undergoing simultaneous heat and mass transfer. Drying Technology 19, 1441- 1460.

Yao, Z., \& Le Maguer, M. 1996. Mathematical modelling and simulation of mass transfer in osmotic dehydration processes. Part I: Conceptual and mathematical models. Journal of Food Engineering 29(3-4), 349-360.

Zhang, J., Datta, A. K., \& Mukherjee, S. (2005). Transport processes and large deformation during baking of bread. American Institute of Chemical Engineers Journal, 51(9), 2569-2580. 


\section{KU LEUVEN}

\section{LIST OF FIGURES}

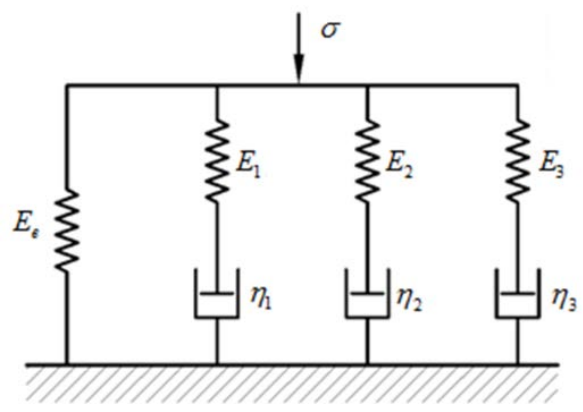

Fig. 1 Generalized Maxwell model

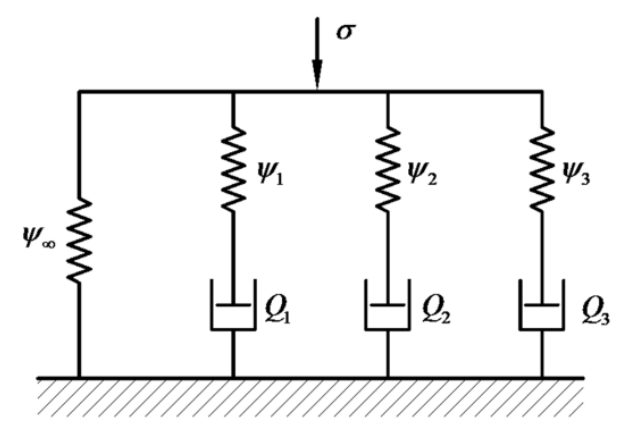

Fig. 2 Maxwell rheological model

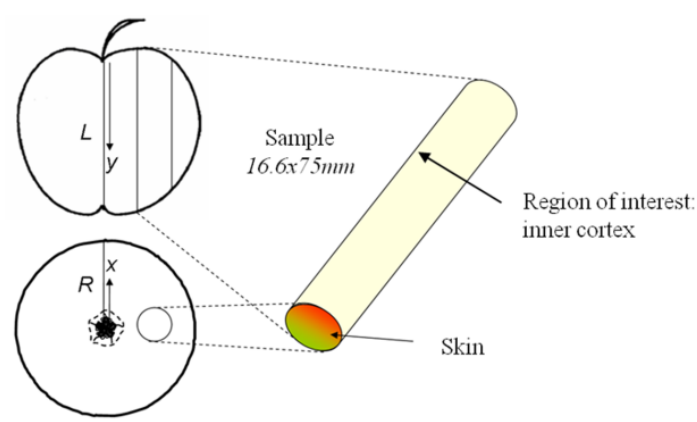

Fig. 3 A schematic view of apple cortex sample preparation for an X-ray CT experiment.

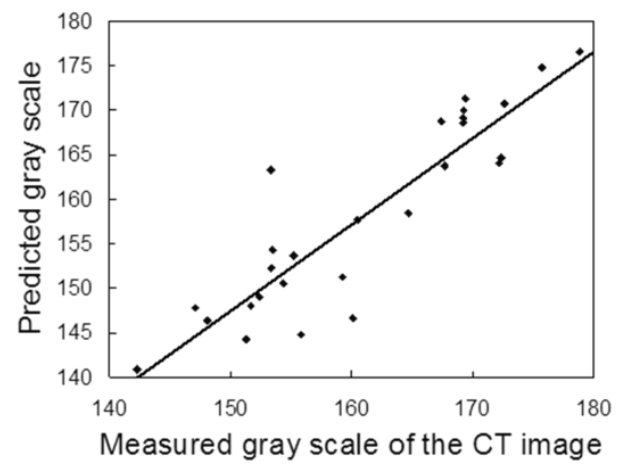

Fig. 4 Calibration of the X-ray CT measurements for a water content range of 2.0 to $6.5 \mathrm{~kg}_{\mathrm{w}} \mathrm{kg}_{\mathrm{dm}}^{-1}$, using Eq. (49), $R^{2}=0.85$. 


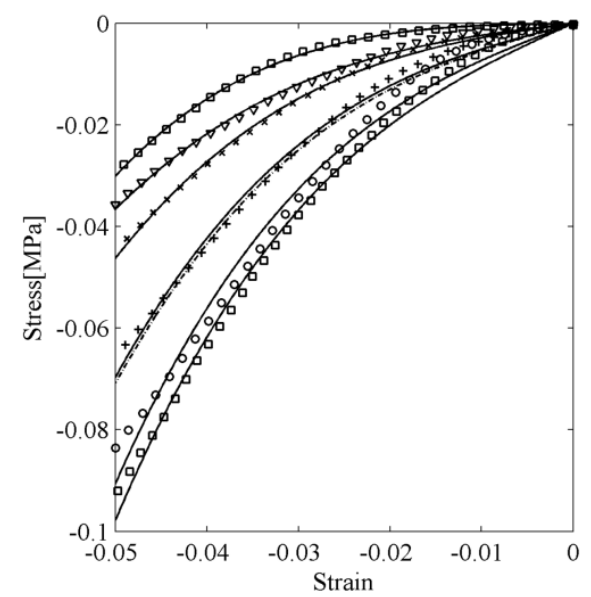

Fig. 5 Stress-strain response of experimental data and constitutive model fit of the strain rate dependent stress response of six samples of apple cortex tissue for a compression-relaxation test. The symbols represent the measurements; the solid lines are the corresponding fittings. The dash dot line is the mean of fittings.

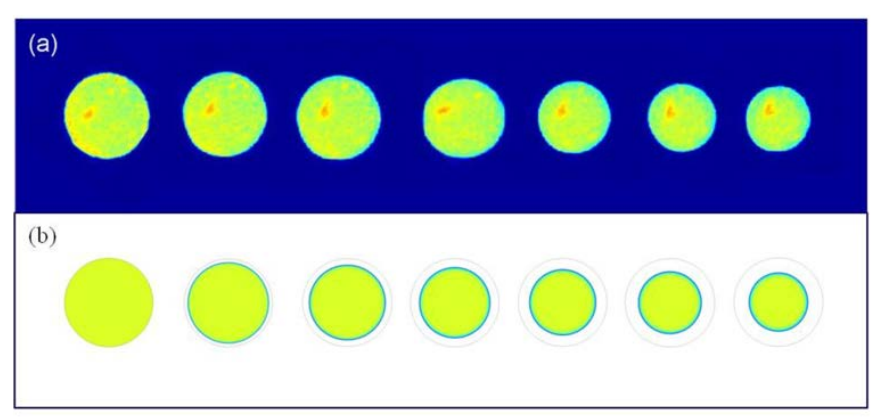

Fig. 6 (a) X-ray CT images of apple (cv. Jonagored) cortex tissue as a function of dehydration time (red: high moisture content, blue: low moisture content) at $30 \% \mathrm{RH}, 20^{\circ} \mathrm{C}$, (b) corresponding nonlinear viscoelastic model simulation with Yeoh hyperelasitc potentials.

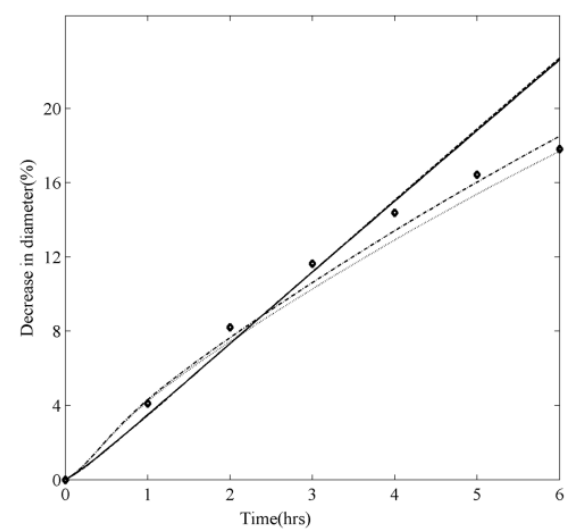

Fig. 7 Shrinkage of apple (cv. Jonagored) cortex tissue during the dehydration experiment $\left(20^{\circ} \mathrm{C}, 30 \% \mathrm{RH}\right)$ and from the corresponding simulation with different models. X-ray CT $(\diamond)$, nonlinear viscoelastic model with Mooney-Rivlin hyperelastic potential (dot line), nonlinear viscoelastic model with Yeoh hyperelastic potential (dash-dot line), linear viscoelastic model (solid line) and linear elastic model (dash line). 


\section{KULEUVEN}

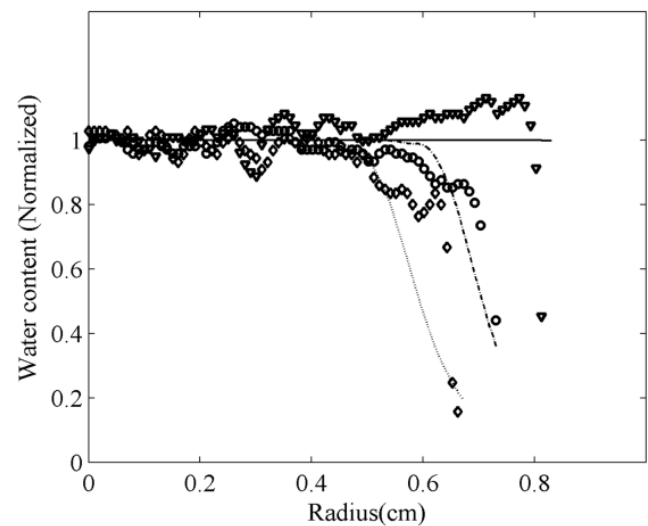

Fig. 8 Water content profile inside the apple inner cortex sample (cv. Jonagored) during the dehydration experiment at $30 \% \mathrm{RH}$ and $20^{\circ} \mathrm{C}$ and the corresponding nonlinear viscoelastic model simulation with Yeoh hyperelastic potential. X-ray CT 0 hour $(\nabla), 3$ hour (o) and 6 hour $(\diamond)$. The solid, the dash-dot and dot lines are respectively the corresponding model simulations.

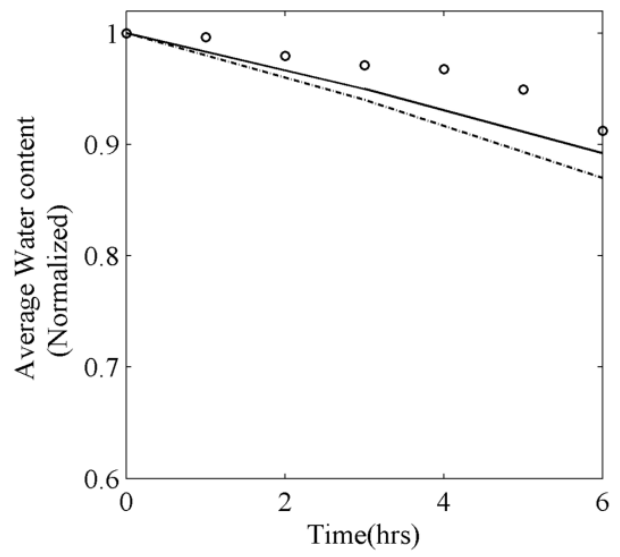

Fig. 9 The normalized average moisture content of cortex tissue: X-ray CT (o). The solid and dash-dot lines are respectively model with shrinkage and model without shrinkage. 


\section{KU LEUVEN}

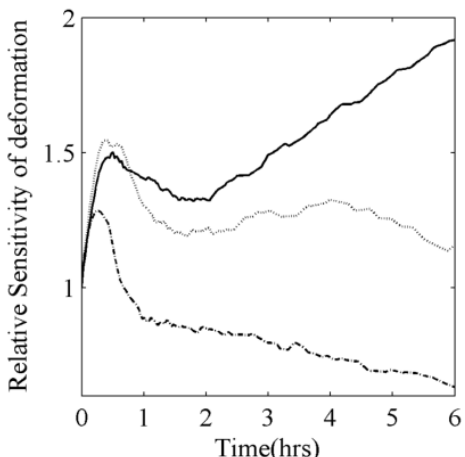

a)

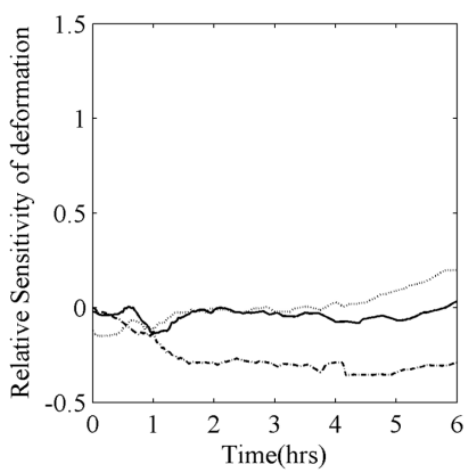

d)

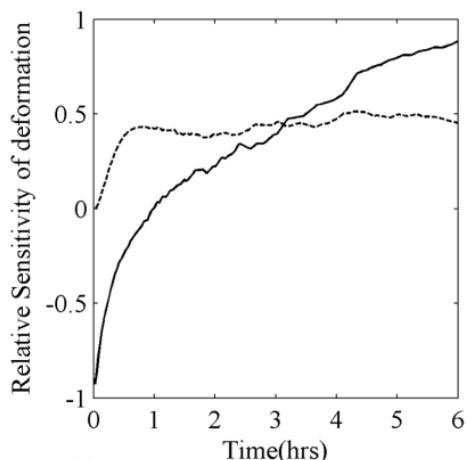

b)

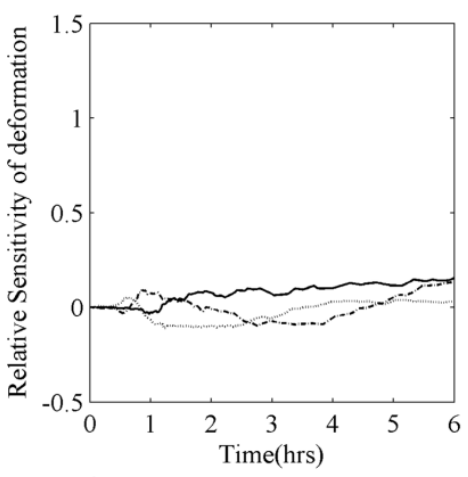

e)

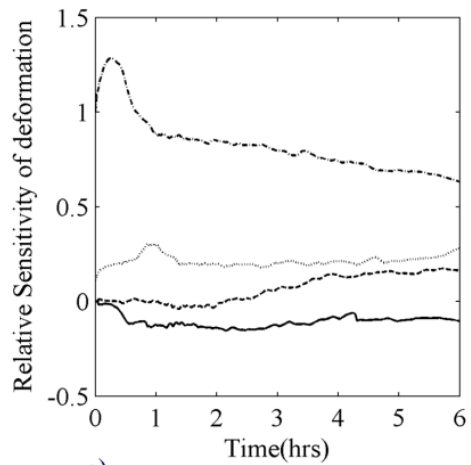

c)

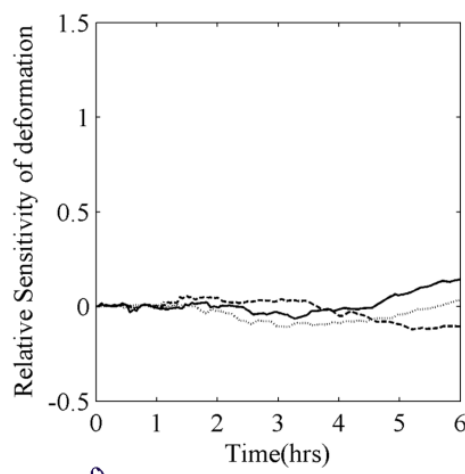

f)

Fig. 10 The sensitivity of the model to different parameters. Water transport parameters (a): $\beta$ (solid line), $h_{m}$ (dot line) and $\rho_{d m}$ (dash-dot line). Water transport parameters (b): $X_{0}$ (solid line) and $K$ (dash line). Yeoh hyperelastic parameters (c): $C_{01}$ (solid line), $C_{11}$ (dash line), $C_{10}$ (dash-dot line) and $\kappa$ (dot line). Mooney-Rivlin hyperelastic parameters (d): $C_{1}$ (solid line), $C_{2}$ (dot line) and $C_{3}$ (dash-dot line). Viscoelastic nondimensional strain energy factors parameters (e): $\beta_{1}$ (solid line), $\beta_{2}$ (dot line) and $\beta_{3}$ (dash-dot line). Viscoelastic relaxation time parameters (f): $\tau_{1}$ (solid line), $T_{2}$ (dot line) and $T_{3}$ (dash line). 


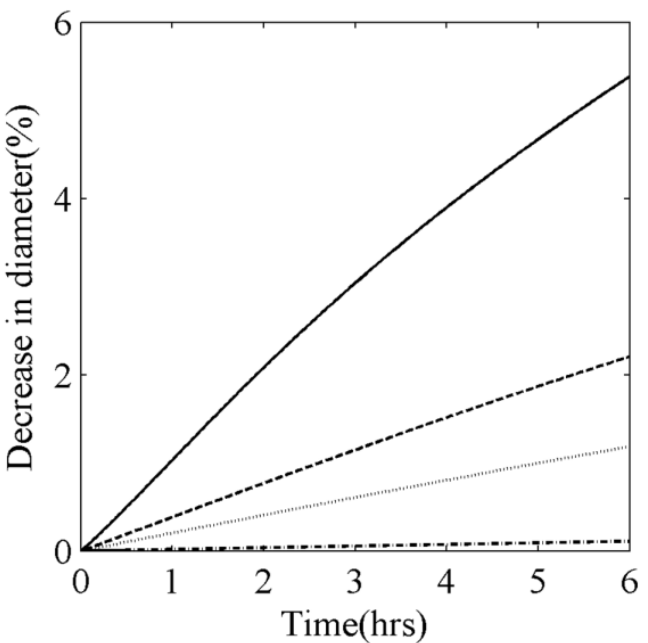

a)

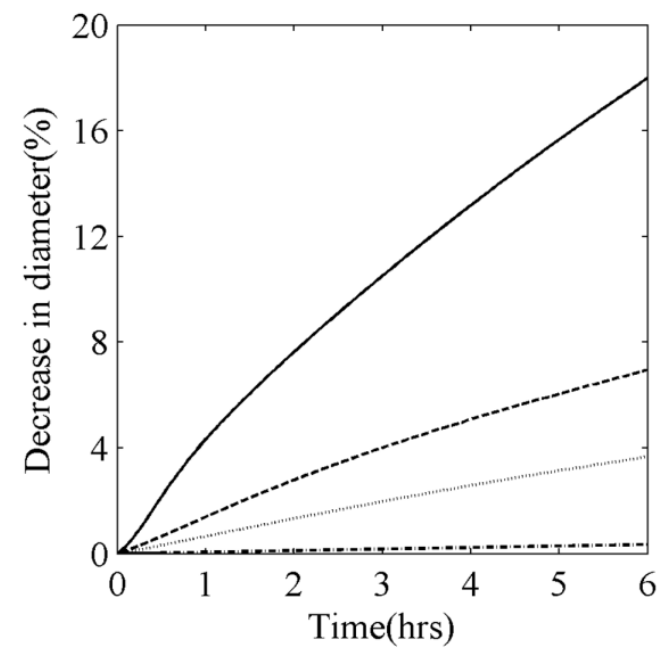

b)

Fig. 11 Shrinkage of apple (cv. Jonagored) cortex tissue during the dehydration experiment. (a) at $1{ }^{\circ} \mathrm{C}$ for different $\mathrm{RH}$ : the solid, dash, dot and dash-dot lines represents respectively the dehydration at $30 \%$, at $60 \%$ at $75 \%$ at $95 \%$ relative humidity.(b) at $20{ }^{\circ} \mathrm{C}$ for different $\mathrm{RH}$ : the solid, dash, dot and dash-dot lines represents respectively the dehydration at $30 \%$, at $60 \%$ at $75 \%$ at $95 \%$ relative humidity.

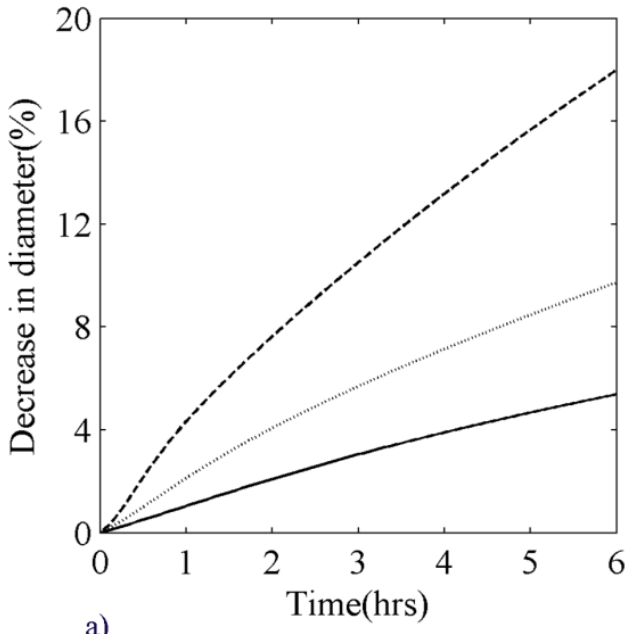

a)

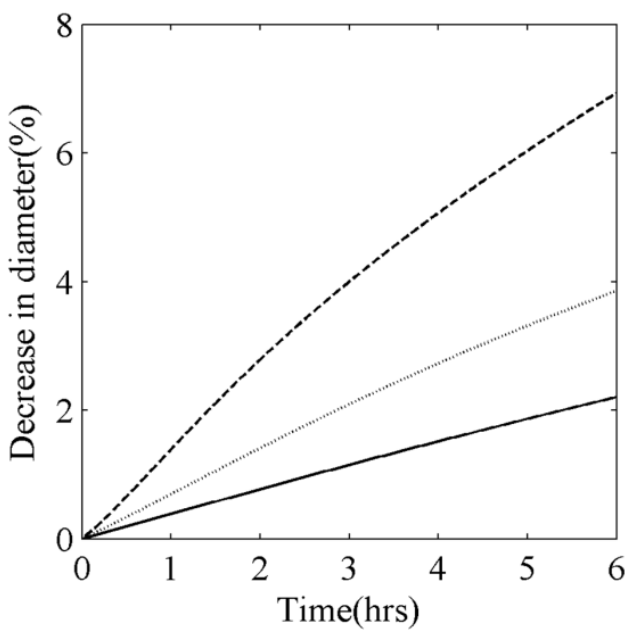

b)

Fig. 12 Shrinkage of apple (cv. Jonagored) cortex tissue during the dehydration experiment. (a) at $30 \% \mathrm{RH}$ for different temperatures: the solid, dot and dash lines represent respectively at $1^{\circ} \mathrm{C}, 10^{\circ} \mathrm{C}$ and $20^{\circ} \mathrm{C}$. (b) at $60 \% \mathrm{RH}$ for different temperatures: solid, dot and dash lines represent respectively at $1{ }^{\circ} \mathrm{C}, 10^{\circ} \mathrm{C}$ and $20^{\circ} \mathrm{C}$. 


\section{LIST OF TABLES}

Table 1 Mass transfer coefficient at different temperatures

\begin{tabular}{ll}
\hline$T\left[^{\circ} \mathrm{C}\right]$ & $h_{m}\left[10^{-13} \mathrm{~kg}_{\mathrm{w}} \mathrm{m}^{-2} \mathrm{~Pa}^{-1} \mathrm{~s}^{-1}\right]$ \\
\hline 0 & 1.024 \\
1 & 1.102 \\
10 & 1.957 \\
20 & 3.530 \\
\hline
\end{tabular}

Table 2 Linear viscoelastic parameters of apple cortex tissue under the relaxation test: average value over 6 samples and standard deviation.

\begin{tabular}{lll}
\hline Parameters & Mean value and standard deviation & Standard deviation \\
\hline$E_{1}[\mathrm{MPa}]$ & $0.469 \pm 0.133$ & $28 \%$ \\
$E_{2}[\mathrm{MPa}]$ & $0.256 \pm 0.080$ & $31 \%$ \\
$E_{3}[\mathrm{MPa}]$ & $0.183 \pm 0.060$ & $32 \%$ \\
$E_{e}[\mathrm{MPa}]$ & $0.464 \pm 0.173$ & $37 \%$ \\
$\tau_{1}[\mathrm{~s}]$ & $524 \pm 161$ & $31 \%$ \\
$\tau_{2}[\mathrm{~s}]$ & $34 \pm 4.34$ & $13 \%$ \\
$\tau_{3}[\mathrm{~s}]$ & $2.93 \pm 0.456$ & $16 \%$ \\
\hline
\end{tabular}

Table 3 Nonlinear viscoelastic parameters of apple cortex tissue under the compression relaxation test: average value over 6 samples and standard deviation.

\begin{tabular}{lll}
\hline Parameters & Mean value and standard deviation & Standard deviation \\
\hline$C_{1}[\mathrm{MPa}]$ & $0.0873 \pm 0.043$ & $49 \%$ \\
$C_{2}[\mathrm{MPa}]$ & $9.492 \pm 2.048$ & $21 \%$ \\
$C_{3}[\mathrm{MPa}]$ & $0.0743 \pm 0.0002$ & $26 \%$ \\
$C_{10}[\mathrm{MPa}]$ & $0.0952 \pm 0.027$ & $28 \%$ \\
$C_{01}[\mathrm{MPa}]$ & $44.179 \pm 9.6$ & $21 \%$ \\
$C_{11}[\mathrm{MPa}]$ & $0.4219 \pm 0.049$ & $11 \%$ \\
$\beta_{1}$ & $0.34 \pm 0.045$ & $13 \%$ \\
$\beta_{2}$ & $0.1862 \pm 0.018$ & $10 \%$ \\
$\beta_{3}$ & $0.1335 \pm 0.015$ & $11 \%$ \\
$\tau_{1}[\mathrm{~s}]$ & $524 \pm 161$ & $31 \%$ \\
$\tau_{2}[\mathrm{~s}]$ & $34 \pm 4.34$ & $13 \%$ \\
$\tau_{3}[\mathrm{~s}]$ & $2.93 \pm 0.456$ & $16 \%$ \\
\hline
\end{tabular}


Research Coordination Office

Huis Bethlehem

Schapenstraat 34

B-3000 Leuven

Tel.: +3216324065

Fax: +3216324198

onderzoek@kuleuven.be

www.kuleuven.be 